\title{
Pediatric cystogram: Are we considering age-adjusted bladder capacity?
}

\author{
Luis A. Guerra ${ }^{1,2,3}$; Melise A. Keays ${ }^{1,2,3}$; M.J. Purser ${ }^{1}$; S.Y. Wang ${ }^{2,3}$; \\ Michael P. Leonard ${ }^{1,2,3}$ \\ ${ }^{1}$ University of Ottawa; ${ }^{2}$ Children’s Hospital of Eastern Ontario (CHEO), Department of Surgery, Division \\ of Urology; ${ }^{3} \mathrm{CHEO}$ Research Institute; Ottawa ON, Canada
}

Cite as: Can Urol Assoc J 2018 June 19; Epub ahead of print. http://dx.doi.org/10.5489/cuaj.5263

Published online June 19, 2018

$* * *$

\section{Abstract}

Introduction: There are a small number of reports in the literature describing bladder rupture during cystograms in children. We hypothesized that children undergoing cystograms may have their bladder overfilled during the test. We aimed to evaluate the current practice when performing cystograms in our institution, contrasting actual volume used to fill the bladder to the age-adjusted bladder capacity.

Methods: We performed a retrospective review of all voiding cystourethrograms (VCUG) and radionuclide cystograms (RNC) performed at the Children's Hospital of Eastern Ontario from 2006-2013. Formulas used to estimate age-adjusted bladder capacity: 1$)$ infants $<1$ year: Capacity $(\mathrm{mL})=(2.5 \mathrm{x}$ age [months] $)+38$ (Holmdahl et al, 1996); and 2) older children $>1$ year: Capacity $(\mathrm{mL})=(2+$ age [years]) x 30 (Koff et al, 1983).

Results: A total of 2411 cystograms were done (1387 VCUG; 1024 RNC) in 817 infants and 1594 children older than one year - 1113 boys and 1298 girls. Generally, bladders tended to be overfilled with $32 \%$ more volume in $\mathrm{mL}$ than the expected age-adjusted bladder capacity — VCUG 151 (122) mL vs 120 (97) mL ( $\mathrm{p}<0.001)$ and RNC 191 (97) $\mathrm{mL}$ vs. 151(74) $\mathrm{mL}(\mathrm{p}<0.001)$. Most importantly, infants had a striking overfilling rate of $64 \%$ and $38 \%$ more volume than their expected age-adjusted bladder capacity for VCUG and RNC, respectively ( $\mathrm{p}<0.001)$.

Conclusion: Bladders are filled above the estimated age-adjusted capacity in $\mathrm{mL}$ at the following rates: $32 \%$ in the whole group and $64 \%$ in infants undergoing VCUG. It raises concern of possible bladder rupture in this age group. Furthermore, this may lead to overgrading and overdiagnosing of vesicoureteric reflux, as well as overestimation of 
post-void residual. Attention should be paid to filling to age-adjusted bladder capacity and allowing the child adequate time to void during performance of the cystogram.

\section{Introduction}

Cystography is one of the most commonly employed diagnostic modalities in pediatric uroradiology. Cystograms may comprise of a voiding cystourethrogram (VCUG) or a radionuclide cystogram (RNC). VCUG involves filling the bladder with a radiocontrast agent via catheterization under fluoroscopy with subsequent voiding. Common indications for VCUG include hydronephrosis, pediatric febrile urinary tract infection (UTI), or bladder diverticulum [1]. VCUG is the most common method of diagnosing vesicoureteral reflux (VUR) and/or posterior urethral valves [1]. RNC is a nuclear imaging study used mainly in the follow-up of known VUR, as it requires significantly lower radiation doses to detect VUR but does not provide the anatomical resolution necessary for reliable diagnosis of posterior urethral valves or grading of reflux [2,3].

While complications arising from cystography are rare, they may include allergic reactions to the contrast material, knotting of the bladder catheter, dysuria, UTI, trauma to the urethra and/or bladder, or bladder rupture [4-6]. Bladder rupture is arguably the most dire complication due to cystography, thus all possible steps to avoid it should be undertaken.

One of the proposed mechanisms of bladder rupture, especially in the setting of pediatric cystography, is bladder over-filling. Accurate estimates of bladder capacity (BC) in children are essential not only for reliable urodynamic assessments, but also to prevent inappropriate filling of the bladder. However, there is very little data regarding the use of age-adjusted bladder filling volumes for cystography available in the literature.

Therefore, we hypothesized that children undergoing cystograms may have their bladders over-filled. This study aims to evaluate the current practice at our institution for performing cystograms, to record the actual volume used to fill the bladder, and to correlate this volume with the calculated age-adjusted bladder capacity.

\section{Methods}

Institutional research ethics board approval was obtained prior to the start of data collection. The medical records of all patients who had a cystogram (VCUG and/or RNC) at the Children's Hospital of Eastern Ontario (CHEO) from 2006-2013 were reviewed.

\section{Inclusion/exclusion criteria}

Inclusion criteria included: 1 ) age $\leq 18$ years old at the time of cystography; 2) maximum bladder filling volume recorded; 3) completed study; 4) medical records available for review. Exclusion criteria included: 1) multiple bladder fillings; 2) technical difficulties; 3) neurogenic bladder; 4) previous bladder injury; 5) large bladder diverticulum; 6) cloacal or bladder exstrophy; 7) ambiguous genitalia. 


\section{Clinical data}

Patients' medical charts were reviewed and the following information was extracted: 1 ) gender; 2) age; 3) maximum bladder filling volume; 4) presence of VUR and/or hydronephrosis.

\section{Estimated bladder capacity}

Age-adjusted bladder capacity was estimated using the following formulas: 1) Bladder Capacity (mL) for infants younger than 1 year old = [2.5 x Age (months) +38 [7]; 2) Bladder Capacity (mL) for children older than 1 year old $=[2+$ Age (years) $]$ x 30 [8].

\section{Statistical analysis}

Results were presented as descriptive analysis using tables and graph. Data was analyzed using SAS ${ }^{\circledR}$ software $\left(\right.$ SAS $^{\circledR}$ Institute Inc., NC, USA). Statistical analysis was performed using unpaired, two-tailed student t-test and linear regression, and $\mathrm{p} \leq 0.05$ was considered significant.

\section{Results}

There were a total of 2579 patients who had a cystogram at CHEO from 2006-2013. Of these patients, 2411/2579 (93\%) met inclusion criteria. The indications for having a cystogram are outlined in Figure 1.

Gender distribution was 1113 male and 1298 female. The age and gender breakdown of the patients are shown in Table 1.

The average volume of contrast used to fill the bladder via catheter during the VCUG for the whole group was 151mL (SD 122), compared to an average estimated bladder capacity of $120 \mathrm{~mL}$ (SD 97), which represented a $+31 \%$ difference ( $<<0.001)$. For RNC the average volume used was $191 \mathrm{~mL}$ (SD 97) compared to the average estimated bladder capacity of $151 \mathrm{~mL}$ (SD 74), which represented a $+33 \%$ difference $(\mathrm{p}<$ 0.001 ). When stratified by age, infants undergoing VCUG had an average fill of $76 \mathrm{~mL}$ (SD 36) compared to an estimated bladder capacity of 43mL (SD 7), which represented a difference of $+64 \%(p<0.001)$ (Table 2$)$.

\section{Discussion}

Cystography, which includes VCUG and RNC, is a commonly used technique to evaluate reflux and urinary tract anatomical defects. Use of appropriate volumes of contrast material to fill the bladder during cystography is essential in preventing bladder overfilling, and potential complications such as bladder rupture. This study reviewed data for children who had a cystograms in order to compare the bladder fill volume used against the patient's calculated age-adjusted bladder capacity.

We found that bladder fill volumes used during cystograms performed at our institution from 2006-2013 were consistently in excess of the estimated bladder capacity of the patients [Table 2]. Specifically, the mean fill volumes used on children of all ages 
who received either a VCUG or RNC were 31\% and 33\% greater than their average estimated bladder capacity. The greatest discrepancy was observed in infants $<1$ year old having a VCUG, such that the mean fill volume used was on average $64 \%$ larger than the estimated bladder capacity for these patients [Figure 2].

The bladder, similar to all organs, tends to grow as a child ages. As a result, the bladder capacity of children is not static, but rather increases with age. Therefore, formulas used to estimate bladder capacity must account for this variance. Several formulas exist for estimating bladder capacity in children of varying ages [7-9], but no single method is consistently used, nor has been thoroughly validated in all age groups. However, the formula devised by Koff et al. (1983) is the one most commonly used in practice to calculate an age-specific bladder capacity, especially in young children, and so was the formula employed in this study to calculate estimated bladder capacity in all children $>1$ year old. The rapid change in bladder growth that occurs during an infant's first year of life has led to the creation of specific formulas for estimating bladder capacity within this age group. The formula created by Holmdahl et al. (1996) is thought to represent the most accurate estimation of bladder volume in infants, and so was used in this study to estimate bladder capacity in all patients $<1$ year old.

Over-filling of the bladder during cystograms raises the possibility of inducing clinically irrelevant vesico-ureteric reflux (VUR), overestimating post-void residual, and in rare cases may cause bladder rupture. We found evidence of VUR in 946/2411 (39\%) of patients. While it is intriguing to consider the potential for VCUG and/or RNC to have contributed to the reflux observed at the time of the study secondary to bladder overfilling, we did not find a significant correlation between these two values in our cohort. Specifically, when we separated patients with observed VUR into low (grades 1-3) and high (grades 4-5) there was no significant association between grade of reflux and degree of bladder over-filling $(\mathrm{p}<0.5)$. This held true for both older children and infants, where the greatest degree of over-filling was observed. While there is little data available in the literature examining the potential contribution of VCUG to over-estimating the severity of VUR [10,11], this is still a likely possibility given the degree of bladder over-filling observed in our cohort. Moreover, because management of reflux is influenced by severity, over-grading of VUR due to bladder over-filling at the time of cystogram may lead to inappropriate management.

Similarly, assessment of post-void residual following a cystogram may also be compromised secondary to bladder over-filling. Bladder distention is one of the primary factors leading to over-estimation of post-void residual in pediatric patients [11]. Therefore, filling the bladder to volumes greater than its natural capacity is likely to subsequently increase the remaining bladder volume post-void.

In general, risk factors for pediatric bladder rupture include posterior urethral valves, neurogenic bladder, bladder augmentation, and bladder outlet obstruction related 
to trauma or other causes [12]. While there are very few cases of bladder rupture post cystogram documented in the literature [12-18], the majority of case reports describe patients under 2 years old. This is in keeping with our finding that the greatest degree of bladder over-filling in cystograms occurred in infants $<1$ year old undergoing VCUG. None of the 2411 patients included in this study had documented bladder rupture at the time of their cystogram. However, the potential for bladder over-filling in the setting of cystography to exacerbate VUR or bladder rupture exists, and so should be considered when administering these tests.

By using objective endpoints such as gender, age, bladder fill volumes used, and presence vs absence of VUR and/or hydronephrosis, we were able to limit much of the subjectivity and potential for variance normally inherent in retrospective studies. Additionally, the degree of significance detected comparing fill volumes and bladder capacities in a cohort as large as ours speaks to the degree of discrepancy between these values.

The primary limitation of this study would be the potential for under- or overestimation of bladder capacity using the formulas by Holmdahl et al. (1996) and Koff et al. (1983). However, as has already been discussed, these 2 formulas are possibly the most common ones used for estimating bladder capacity in pediatric population. Another limitation is that children with large volume VUR can accept larger volumes of filling due to passive reflux during the filling phase. One other potential weakness is that some infants with VUR have larger than expected bladder capacities as documented by Sillen et al [7]. As a result, these children would not have true bladder over-filling as would be expected based on their estimated bladder capacities.

\section{Conclusion}

In conclusion, this is believed to be one of the first and largest studies to demonstrate a significant difference between the volume of contrast used to fill the bladder during cystograms in children, and the estimated bladder capacity of these patients. We have shown that cystograms in children are prone to bladder over-filling, especially within the first year of life, and that this current trend could account for reported inaccuracies of cystograms such as exacerbating the severity of VUR and falsely elevated post-void residual. Bladder rupture may also occur, albeit rare. Attention should be paid to fill to age-adjusted bladder capacity, and to allow adequate time for the child to void in a relaxed environment. However, this practice must be balanced with the busy schedule of the radiology department and the concern of missing significant VUR due to bladder under-filling. 


\section{References}

1. Reddy Pramod P. Recent advances in pediatric uroradiology. Indian J Urol. 2007 Oct-Dec;23(4):390-402.

2. Fretzayas A, Karpathios T, Dimitriou P, Nicolaidou P, Matsaniotis N. Grading of vesicoureteral reflux by radionuclide cystography. Pediatr Radiol. 1984;14(3):148-50.

3. Roach PJ, Treves ST. Radionuclide cystography: a review of its use in adults. Q J Nucl Ned. 1996 Dec;40(4):372-7.

4. Zerin JM, Shulkin BL. Postprocedural symptoms in children who undergo imaging studies of the urinary tract; is it the contrast material or the catheter? Radiology. 1992 March;182(3):727-30.

5. Gonzalvez PJ, Fernandez CM, Vidal CA. Intravesical knot of Foley catheter: unusual complication of cystourethrography in children. An Esp Pediatr. 2000 Dec;53(6):601-3.

6. Agrawalla S, Pearce R, Goodman, TR. How to perform the perfect voiding cystourethrogram. Pediatr Radiol. 2004 Feb;34(2):114-19.

7. Holmdahl G, Hanson E, Hanson M, Hellstrom A, Hjalmas K, Sillen U. Four-hour voiding observation in healthy infants. Journal of Urology. 1996;156:1809-1812.

8. Koff SA. Estimating bladder capacity in children. Urology. 1983;21(3):248.

9. Kaefer M, Zurakowski D, Bauer SB, Retik AB, Peters CA, Atala A, Treves ST. Estimating normal bladder capacity in children. Journal of Urology. 1997;158(6):2261-2264.

10. Bomalaski MD, Hirschl RB, Bloom DA. Vesicoureteral reflux and ureteropelvic junction obstruction: association, treatment options and outcome. J Urol. 1997;157(3):969-74.

11. Lebowitz RL, Blickman JG. The coexistence of ureteropelvic junction obstruction and reflux. AJR Am J Roengenol. 1983;140(2):231-8.

12. Seibold J, Alloussi S, Werther M, Schwentner C, Sievert KD, Stenzl A. Presenting a new non-invasive diagnostic tool in estimating bladder capacity in healthy children: the abc (age-related bladder capacity)-formula. J Pediatr Urol. 2010 April;6(1):100-01.

13. Elsamra SE, Gordon Z, Ellsworth PI. The pitfalls of Bladder Scan PVR in evaluating bladder volume in adolescent females. J Pediatr Urol. 2011;7(1):95-7.

14. Trulock TS, Finnerty DP, Woodard JR. Neonatal bladder rupture: case report and review of literature. J Urol. 1985;133:271-3.

15. Cam $\mathrm{H}$ et al. Bladder rupture following voiding cystourethrography . Indian Pediatr. 2006 Feb;43(2):179-80. 
16. Kajbafzadeh AM, Saeedi P, Sina AR, Payabvash S, Salmasi AH. Infantile bladder rupture during voiding cystourethrography. Int Braz J. 2007 Jul-Aug;33(4):532-5; discussion 535.

17. Khavari R, Bayne AP, Roth DR. A report of an iatrogenic bladder rupture in a normal healthy child during voiding cystourethrography. Urol. 2010 Mar;75(3):684-6.

18. Lee KO, Park SJ, Shin JI, Lee SY, Kin KH. Urinary bladder rupture during voiding cystourethrography. Korean J Pediatr. 2012 May;55(5):181-4.

19. Oktar T Sanli O, Atar A, Ozcan F, Ander H, Ziylan O. Iatrogenic bladder rupture in a child following voiding cystourethrography and its laparoscopic management. Eur J Pediatr Surg. 2011 Aug;21(4):275-7.

20. Resinger W, Thrall J. Diagnosis of ruptured bladder during a 99mTc-DTPA renal study: new indications for radionuclide cystography? Clin Nucl Med. 1979 May;4(5):179-80.

21. Wosnitzer M, Shusterman D, Barone JG. Bladder rupture in premature infant during voiding cystourethrography. Urol. 2005 Aug;66(2):432. 
Figures and Tables

Fig. 1. Indications for cystograms (VCUG or RNC). PUV: posterior urethral valves;

RNC: radionuclide cystogram; UTI: urinary tract infection; VCUG: voiding cystourethrograms; VUR: vesicoureteral reflux.

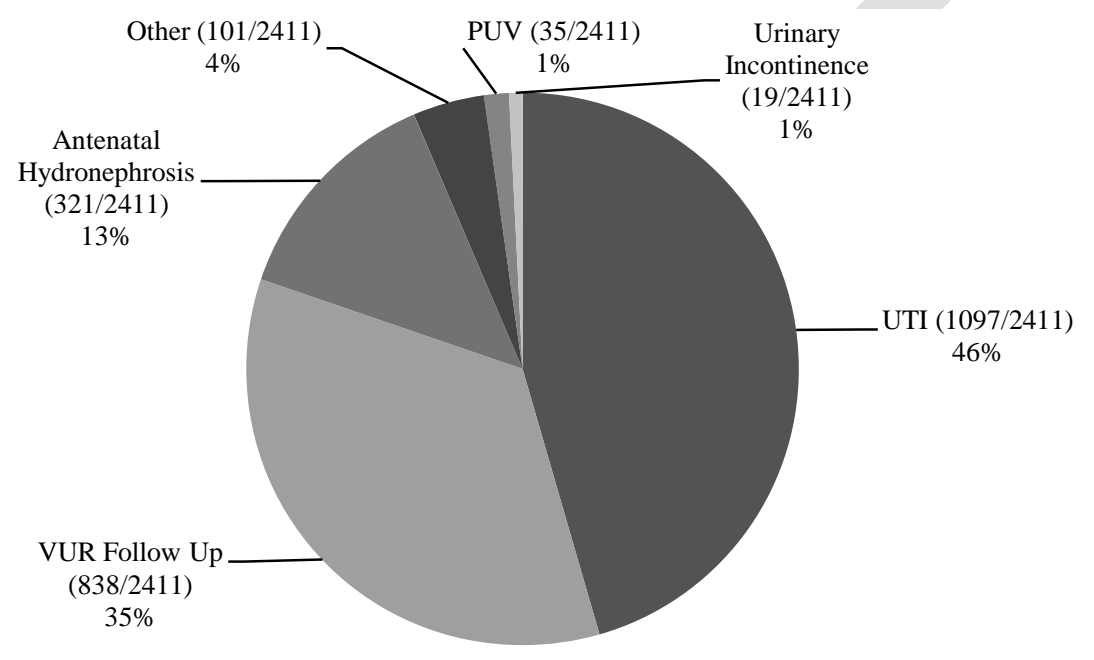

Fig. 2. Comparison of mean fill volumes used during infantile cystograms with patients' ideal estimated bladder capacities.
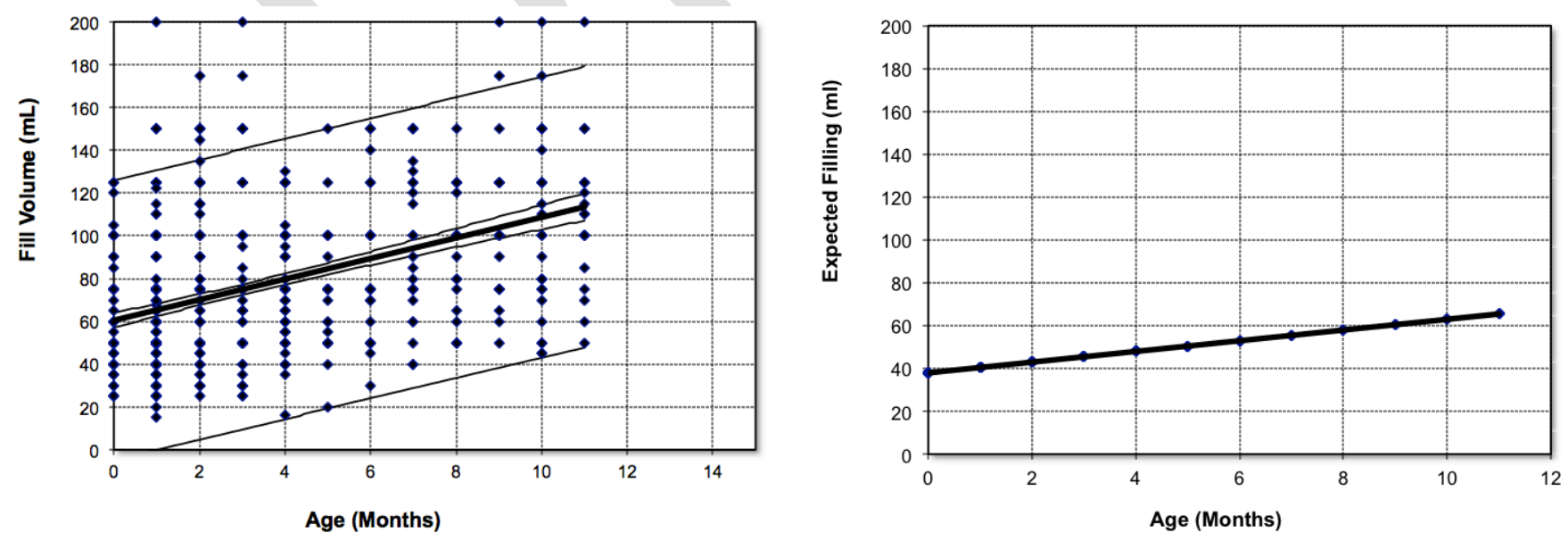

$R^{2}=1$ 
Table 1. Overview of patient cohort demographics

\begin{tabular}{|l|c|c|c|c|c|c|c|c|}
\hline & Overall & $\begin{array}{c}\text { Infants } \\
(<\mathbf{1 y r})\end{array}$ & $\begin{array}{c}\text { Children } \\
(>\mathbf{1 y r})\end{array}$ & $\begin{array}{c}\text { Mean age, } \\
\text { years } \\
\text { (SD) }\end{array}$ & Male & Female & VUR & Hydronephrosis \\
\hline VCUG & 1387 & 761 & 626 & $2.3(3.0)$ & 747 & 640 & 335 & 455 \\
\hline RNC & 1024 & 56 & 968 & $3.5(2.5)$ & 366 & 658 & 611 & 212 \\
\hline Total & 2411 & 817 & 1594 & & 1113 & 1298 & 946 & 667 \\
\hline
\end{tabular}

RNC: radionuclide cystogram; SD: standard deviation; VCUG: voiding cystourethrograms; VUR: vesicoureteral reflux.

\begin{tabular}{|c|c|c|c|c|}
\hline & $\begin{array}{c}\text { Mean fill } \\
\text { volume, } \mathrm{mL} \text { (SD) }\end{array}$ & $\begin{array}{l}\text { Estimated bladder } \\
\text { capacity, mL (SD) }\end{array}$ & Difference & $\mathbf{p}$ \\
\hline \multicolumn{5}{|l|}{ VCUG } \\
\hline Infants $<1$ year & $76(36)$ & $43(7)$ & $+64 \%$ & $<0.001$ \\
\hline Children $>1$ year & 243 (129) & 195 (105) & $+38 \%$ & $<0.001$ \\
\hline Overall & $151(122)$ & $120(97)$ & $+31 \%$ & $<0.001$ \\
\hline \multicolumn{5}{|l|}{ RNC } \\
\hline Infants $<1$ year & $69(34)$ & $53(9)$ & $+26 \%$ & 0.0016 \\
\hline Children $>1$ year & $198(95)$ & $156(73)$ & $+34 \%$ & $<0.001$ \\
\hline Overall & $191(97)$ & $151(74)$ & $+33 \%$ & $<0.001$ \\
\hline
\end{tabular}

RNC: radionuclide cystogram; SD: standard deviation; VCUG: voiding cystourethrograms. 